\title{
INTERNATIONAL OCEANOGRAPHIC CONGRESS
}

$\mathrm{I}^{\mathrm{N}}$ spite of the increasing application of scientific discoveries to development of weapons and to enhance national prestige, we can still maintain that science is one of the most international of intellectual activities, and hold that anything we can do to promote co-operation is likely to contribute to better understanding between nations. If not generally true, it must still be so for the study of the oceans, with its very wide and numerous bearings on human welfare, and it seems very appropriate that the first International Oceanographic Congress, which took place during August 31-September 11, should have been held in the United Nations headquarters in New York; also that it should be sponsored by the American Association for the Advancement of Science, which has ably demonstrated the part science can play in raising the level of economic prosperity, and by Unesco, which strives to spread the educational, cultural and practical benefits to all nations. Oceanographers have a tradition of working together, and have a number of intergovernmental councils and scientific associations to help them, but this was probably the first time such a grand attempt had been made to assemble enthusiasts from every aspect of the subject and all parts of the world.

The aim was to get to know and help each other, and the programme was arranged around five main topics: "History of the Oceans", "Populations of the Sea", "The Deep Sea", "Boundaries of the Sea", and "Cycles of Organic and Inorganic Substances in the Sea". Each theme had two morning sessions, with lecturers invited to review contemporary advances rather than the older published work, and in the afternoons the audience divided among four discussions of papers related to the morning topics. The main purpose of the conference seemed to be very well achieved : a great deal of unpublished work was discussed and new ideas freely exchanged. Everyone writing about it will be sure to say how wonderful was the exchange of information between people who knew each other or had read each other's papers. The success was largely due to the efforts of the organizing committee, which persuaded oceanographic laboratories all over the world to send the younger members of their staffs as well as directors, and to the generous financial help of some twenty-two government and private organizations in the United States, which overcame much of the difficulty of travel expenses.

The "History of the Oceans" section dealt with the shape and structure of the ocean basins, the forces involved, the history of sea water, and the origin of life. We begin to know enough about the topography of the Atlantic and Pacific Oceans to form a reasonable overall picture and to know where to study the processes at work. Earthquake activity, vulcanicity, gravity and magnetic anomalies are beginning to be related to topography. The abyssal plains are as interesting as the ridges. We still do not know whether continental slopes are rubbish tips or weathered rock. We were warned against too ready acceptance of generalizations attributing all acid rocks found in dredges to transport by ice. There should be more active studies to see if they could be locally derived, and to see if they can be dated; we were told to be careful about giving them to museums. Another caution, from the biologists, was that while those dealing with living material are very careful about drawing conclusions beyond simple description or regional relationships, palæographers showed less hesitation in making positive deductions about ancient seas. The physicists agreed that the difficulty of finding hypotheses to explain the present circulation of the oceans made it quite fantastic to put forward conclusions about those of earlier climatic periods. There are, nevertheless, very exciting attempts to obtain evidence from the stratigraphy, chemistry, physics, biology and nuclear relationships of the sediments. The same types of evidence, and increasingly penetrating studies of the chemistry of sea water and of its exchanges with the sediments, are also beginning to provide a better framework for judging ideas on the origin of life in the sea.

In "Populations of the Oceans", most of the papers and discussions were on biogeography, distribution and behaviour in relation to physiology and environment, evolution and adaptation, and palæobiogeography. One of the morning lectures was a fascinating unpublished study of the distribution of bottom-living organisms in relation to the time they spent in the pelagic larval stage. It was shown that this time varied with temperature, and that metamorphosis could be postponed by unfavourable conditions. There were a relatively large number of papers from the Soviet Union, dealing mainly with the fish, plankton and bottom-living organisms of the Pacific and Antarctic Oceans. Once or twice there was a hint that some of the more special approaches were defending their territories : ethology tried to disclaim a paper which showed how a squid kept itself afloat.

"The Deep Sea" discussions included the physics and chemistry of circulation, stirring and mixing, the nature and origin of bathypelagic life, the special characteristics of abyssal organisms and the distribution of pelagic-sediment types and nuclear processes in pelagic sediments. During discussion of a Soviet study of turbulent diffusion which confirmed some previous work by the late L. F. Richardson, it was very pleasant to see the charm with which Dr. Henry Stommel, probably the only one there who had talked with Richardson, greeted what might be the only mention of his name in the United Nations headquarters with timely reference to his mathematical treatment of foreign politics, arms and insecurity.

There was plenty of evidence that new ideas on turbulent processes are being profitably applied to the study of vertical and horizontal movements and to better understanding of internal waves. One of the most striking diagrams showed the unexpected complexity of the north and south movements below the Gulf Stream. Even more remarkable was one which contoured velocity in a north-to-south vertical section across the sub-surface 'Cromwell' current, below the equator in the Pacific Ocean. It showed a thin ribbon of water some 100 metres thick and 100 miles wide flowing eastwards at about $2_{2}^{1}$ knots, 
mainly between depths of 50 and 200 metres, symmetrical about the equator and known to occur over most of the width of the Pacific Ocean, while all the adjoining water, above, below, north and south, flows in the opposite direction. Interpretation of previous climates from the study of the stratigraphy of the deep-sea sediments seems to be one of the most popular oceanic studies, and there was a strong plea for samples of older sediments from depths well below the level attainable by coring. Quite shallow bore-holes would give information as valuable as the much discussed deep bore. It might be easier to plot previous positions of the equator from the carbonate content of the sediments than to plot previous positions of the poles from evidence of previous magnetism. Most of the geologists seem to feel that there ought to be a much greater depth of sediments in the ocean.

Discussions on "Boundaries of the Sea" dealt with the effects of land masses and types of coast and sea bottom on the plant and animal populations. The rather special conditions in bays and estuaries were emphasized. The physical papers dealt with the nearshore circulation. One of the most striking papers gave a preliminary survey of the very complex thermal structure in the Straits of Gibraltar obtained with the new towed chain of thermistors. Prof. W. H. Munk's morning lecture on the spectrum of sea-level, from ordinary waves to changes in mean sea-level, was one of the most appreciated by the Congress, and the relevant afternoon discussion dealt with a wide range of contributions about effects of pressure, wind, climate and seismic disturbances. Further afternoons were devoted to the interchange of energy between sea and air, and to proposed methods for predicting surface conditions and changes in currents. There was a very interesting account of observations relating surface slicks to internal waves in a shallow thermocline. The internal waves travelled in the same direction as the surface waves and the slicks also moved slowly in the same direction.

The section on "Cycles of Organic and Inorganic Substances" included discussions of the chemistry of sea water, the occurrence of biologically active substances, including vitamins and trace elements, primary production, nutrient relationships, balance between living and dead organic matter, exchanges between the sea and sediments and between the sea and atmosphere. C. E. Lucas and J. H. Steele of Aberdeen and L. H. N. Cooper of Plymouth gave morning lectures. There was enough in this section alone to make a conference.

One of the most striking features of the Congress was its evidence of the expanding interest of geologists in the ocean. Biology, for the first time at such a meeting, probably took second place, and except for the new Soviet expeditions it tended to be concentrated in waters not far from shore. The physics of the sea had a good deal to show for the first time, and, not least significant, it could at last be seen to be making observations to check theories.

The morning lectures will be published, and everyone attending the Conference had preprints of abstracts of all the papers contributed to the discussions, a very formidable volume of 1,027 pages. The simultaneous translations provided by the United Nations staff in English, French and Russian were magnificent. We were able to carry on active discussions with Soviet scientists and occasionally listen to them arguing with each other. The facilities of the United Nations building for a large assembly with discussion groups are quite extraordinary. Most of the 1,200 who registered for the Congress seemed to be staying at the Commodore Hotel only a few blocks away, and there was always someone interesting to talk to. The Soviet research ship Michael Lomonosov, and five American ships, Atlantis, Chain, Crawford, Maury and Gibbs were lying at one pier and the French Calypso at another. There was a good programme of social events including a particularly agreeable visit to the New York Zoological Park.

One might penetrate deeper into the science at a smaller meeting, but there could be no better way of getting an impressive though perhaps general idea of the increasing interest and advance in all aspects of the subject. For everyone except the organizers it was in fact rather a holiday, and at the same time a most remarkable opportunity for forming new ideas, correcting old ones and thinking what to do next. There can be no doubt that some of the work begun there will be continued in growing friendliness by scientists all over the world. All marine scientists, and especially those privileged to attend, owe a great debt to Dr. Mary Sears and her organizing committee, to all others who helped, and not least to the United Nations.
G. E. R. Deacon

\section{DEVELOPMENTS IN THERMODYNAMICS}

\begin{abstract}
A SYMPOSIUM on Thermodynamics was held during August 20-25 at Fritzens-Wattens, near Innsbruck, Austria, under the joint sponsorship of the Deutsche Bunsen Gesellschaft für Physikalische Chemie, and the International Union of Pure and Applied Chemistry, the latter through its Commission on Thermodynamics, the Sub-Commission on Experimental Thermochemistry and the SubCommission on Experimental Thermodynamics. The symposium was under the general direction of Prof. K. Schäfer (president of the Deutsche Bunsen Gesellschaft für Physikalische Chemie, and secretary of the Commission on Thermodynamics) with the local arrangements being handled by Prof. E. Cremer, of the University of Innsbruck. Fifty papers were
\end{abstract}

read, and there were 135 participants, representing seventeen countries, including thirty from North America and twenty from Great Britain.

\section{Experimental Thermochemistry}

The first part of the symposium, under the general heading "Experimental Thermochemistry", contained twenty-three papers. Fight of these were studies in bomb-combustion calorimetry. The most novel paper of this group, presented by W. N. Hubbard (Argonne, National Laboratory) gave a preliminary account of the successful development of a bomb-calorimeter for combustions in an atmosphere of fluorine gas. The bomb is made of nickel, which is rendered inert to 